\title{
Understanding the Motivation of Nigerian Science Teacher for Sustainable Development
}

\author{
Jacinta A. Opara, PhD \\ Center for Environmental Education \\ Universidad Azteca, Chalco-Mexico
}

Doi:10.5901/mjss.2014.v5n26p101

\begin{abstract}
The role of science in national development has remained important in throughout history. The Science teacher educator is very important for the development of any nation. The main objective of this paper is to contribute to the fact that there is no one best way of Motivating the Nigerian science teacher educator. That the best approach depends on the individual and the circumstances prevailing the workplace. Broadly speaking, motivation consists of a driving force or state of need deficiency which inclines a person to behave in a particular manner, or to develop a capacity for certain type of behaviour. The urge to act in a certain way may be generated by physiological or psychological needs or states including unconscious and conscious thought process or by external stimuli or by some combination of these. People obviously differ widely in these respects, and accordingly their behaviours also differ.
\end{abstract}

Keywords: Human Resources, Motivation, Nigeria, Science Teacher, Educator

\section{Introduction}

Since the 1930's there has been much attention to the role of motivation in worker performance in Nigeria. Earlier technologies for increasing performance, such as the simplification and standardization of work methods and the development of tests of aptitudes and abilities for use in personal selections, made important contributions but were not successful in eliminating wide spreads restriction of output Osuagwu (1984).

Roethlisberger and Dickson (1939) gave impetus to the study of motivational influences in performance as did the experiments of Kurt Lewin and his associates in group decision making and democratic leadership (Lewin Lippitt, and White, 1939). The role of motivational process in determining a workers level of performance is now widely recognized. Connellan (1978) has identified the development of the 'will to work' as industries core problem in the utilization of manpower. Lewin Lippitt and White (1939) indicated the need for greater attention to problems of motivation and frustration by industrial firms. McGregor (1960) and Likert (1961) have also outlined theories of management based largely on assumption about human motivation.

\subsection{Model for Motivating the Nigerian Science Teacher Educator Based on Theories of Motivation}

Motivation is one of the most researched and discussed subject areas in both public and business administration. It is a fact that no matter how good or efficient an organization is, nothing happens until the people who make up the organization are motivated to perform (Opara, 1999). This impetus may be totally internal to the employees, but often it requires the employer to exert an external stimuli's. Researchers have sought to explain how and why people are actual led to behave as they do and how they can be made to behave in a manner supportive of organizational goals.

Several theories have been developed to this end. These include:

a) Abraham Maslow's hierarchy of needs

b) Douglas McGregor's theory $X$ and $Y$

c) Frederick Hertzberg's motivation hygiene theory

d) David McClelland's need to achieve theory

e) B. F Skinner's behaviour modification theory

f) Victor Vroom's valence - expectancy theory

The first three theories are comparable as they all seem to approach motivation from a similar perspective and emphasize similar sets of relationship. They have been observed to be too dependent on the content and context of the study. To Maslow the motivating forces behind the worker are higher level needs which are rarely satisfied by his own estimate, the average citizen is satisfied perhaps $85 \%$ in physiological needs, $70 \%$ in safety needs, $50 \%$ in love needs, 
$40 \%$ in self - esteem needs and $10 \%$ in self actualization needs

To Hertzberg hygiene factor do not motivate but must be in existence to neutralize dissatisfaction before the satisfiers can be applied to promote motivation.

McGregor's approach is based on the assumption that only attitudes based on theory $Y$ can motivate workers.

The Maslow's higher level needs act the same way as Hertzberg's satisfiers and McGregor's theory Y.

McClelland's need to achieve theory maintains that people with a high need for achievement have a completing desire for success and an equally intense fear of failure. A person with a high need to achieve would possess certain characteristics which would make it easier for him to work in some situations than others.

However, that some people exhibits (nach) characteristics and are internally motivated is not disputed but how to infuse some characteristics in people who lack them is the question. The difficult with the theory is therefore, with its application. Besides, it does not present adequate picture of what the motivation and variables affecting workers are and how to carry out training programmes to induce (nach) personality in non (nAch) persons.

In addition, behaviour modification theory states that people can be motivated by properly designing their work environment and rewarding good performances. This theory no doubt has very wide applicability but it requires complex laboratory experimental designs to test 'the effects of 'western' versus 'tribal' orientations on the relationship between enriched work and job satisfaction and performance. He found that 'the relationship between enriched work and job satisfaction was higher for western oriented workers than it is for tribal oriented ones. The significance of Orpen's work for this study appears to be his vivid identification of the motivational potential of certain instruments as they affect the western oriented worker and the relatively less potent form these same instruments were when applied to the tribal oriented worker. Orpen's work also confirms that the Nigerian worker has developed a work culture based on his own thought system.

In a similar vein, Otite (1978) has also argued that 'th behaviour of a people cannot be fully understood unless one knows their systems of thought'. Otite argument appears to be in line with an earlier exposition by Cole (1913). Cole argued that:

'the form in which men cast their speculations no less than the ways in which they behave, is the result of the habits of thought and action which they find around them'.

The beliefs, norms, rituals, traditions and sagas of the Nigerian worker determine what motivates him at work. It is therefore, necessary to study the traditional Nigerian worker very closely to be able to identify his preferences, instead of relying on speculations which are western in orientation and philosophy.

\section{The Nature of Science Teacher Educator as an Employee}

The science teacher educator is a social being who desires to associate with others in order to achieve some of his goals that he might not otherwise be able to achieve alone, perhaps because of physical, biological and mental limitations. An employee has a number of aspirations and goals which he/she wants to achieve through membership of an organization. The organ in question will be able to assist him or her to achieve desired personal goals. The hope and believe that the personal goals and aspiration can be achieved are major motivating factors for an individual's membership of an organization.

Of all the preconditions for effective management of an organization, the most vital is the human resource. The success of any organization is predicate upon the human beings that make up that organization (Akerele, 1992). This is primarily because human beings take decisions, provide the knowledge, energy and cooperation through which organizational objectives are achieved. Other resources have to be coordinated and managed by people for the achievement of organizational objectives. Each individual at work has his or her set of values drives, perception, fears, goals, experiences that inform his/her behaviour at work place. Human labour as a special resource, requiring special attention was for long acknowledged by Karl Max and Federick Engels. Man would pursue social conditions, which will liberate, rather than frustrate or deform his personality development

The science teacher educator as human is a distinctive productive force among other productive forces makes its management problematic and challenging. He reacts in complex ways to decision, social relationships and situation. In most cases, these reactions are unpredictable. Thus despite advanced studies in behavioural sciences, the psychology and sociology of motivation remains a complex area of study (Onoge, 1992) 


\subsection{Social Interaction of the Worker}

Social psychologists typically emphases the fact that teaching is a social activity. Virtually all work roles of the science teacher educator requires social interaction with other people, the students, the parents and government. It's the same way the marketer interacts with his customers, the doctor with his patients, and the supervisor with his subordinates.

Miller and Form (1951) stated that the motives for working cannot be assigned only to economic needs, for men may continue to work even though they have no need for material goods. Even when their security and that of their children is assured, they continue to labour. Obviously this is so because the rewards they get from work are social, such as respect and admiration from their fellow men.

The tendency to gain satisfaction from social relationships has long been recognized as a human attribute. A worker who believes very strongly in a particular Christian religion which is the same as that of the boss could easily be motivated by the playing of Christian records at work. But that same worker may be de-motivated if a manager attempts to motivate him or her using 'gifts' that directly or indirectly connote 'bribery' as a catalyst.

\subsection{Specialization and Job Satisfaction}

Although specialization has been a major guiding principle in the design of jobs for optional productivity, some social scientists asserts that the increased repetitiveness of jobs has not only resulted in greater dissatisfaction and turnover but has also reduced the motivation of workers to perform their jobs effectively Miller and Form (1951)

There is no doubt that increased specialization may increase as well as decrease productivity, but the pressing problem is the understanding of the conditions under which each of these results will be obtained. A great deal has been written about the pleasures and frustrations associated with different kinds of job. Psycholo-analytic theorists have speculated about motives which might explain the intrinsic satisfactions derived from work. In civilization and its discontents, Freud (1949) stressed the opportunity that work afforded individuals for discharging libidinal impulses.

Workers could sublimate their sexual and aggressive impulses and at the same time bind themselves more closely to reality. This idea is explained further by Hendrick (1943) he proposed a modified psychoanalytic view of motivation with his concept of a 'work principle'. He noted that work is not primarily motivated by sexual need or associated aggressions, but by the need for efficient use of the muscular and intellectual tools regardless of secondary needs-self -preservating aggressive or sexual work performance may also satisfy. This is the thesis of the work principle that primary pleasure is sought by efficient use of the central nervous system for the performance of well-integrated ego functions which enable the individual to control or alter his environment.

These motivational concepts although intuitively appealing do not easily lend themselves to empirical test. The basic problem remains what tasks are rewarding under what conditions. Since about 1950, researchers in experimental psychology using animal subjects have made numerous references to rewarding properties of outcomes which are not easily reducible to physiological needs or drives and suggest a motivational system which is more akin to the self actualization tendencies, proposed by Goldestein (1940) and Maslow (1955). The data suggest that higher organisms are rewarded by the opportunity to explore and manipulate their environment. This development, along with parallel trends in psycholoanalytic theory and general psychology, has led White (1959) to propose the concept of reflectance motivation.

\subsection{Wages and Economic Circumstances}

One indisputable source of the desire of people to work is the money they are paid for working. Although one may disagree with monolithic conception of the classical 'economic man' few people would dispute the importance of anticipated economic consequences in the guidance of human conduct (Falade-Obalade and Opara,2010). Despite that money cannot buy happiness; it can be exchanged for many commodities which are necessary for survival and comfort. However, it would be incorrect to link the importance of money in our society strictly to the satisfaction of biological needs. The goods and services that are purchased with money do for beyond insuring survival. They serve, among other things, as an indicator of social status of the purchaser. The connection between the quantity and quality of goods consumed and the status of the consumer

However, the evidence concerning none economic incentives to work are not restricted to peoples report of their motivations. The existence of 'dollar a year men' who work with only token economic rewards and entrepreneurs who continued to work after having amassed tremendous fortunes is well known Vroom (1964). There is at least anecdotal evidence that people actually do return to work after inheriting large sums of money. Brown (1954) mentioned three workers in London factories who won large sums of money from football pools which, if suitably invested, would provide 
enough income to enable the men to live comfortably for the rest of their lives.

In each of the cases, after a short period of leisure, the men returned to work 'two on routine repetitive works' and one as a fitter'. Obviously, it seems clear that for a large proportion of individuals the decision to seek or to continue work is based partly on anticipated rewards obtain from work that have nothing to do with money or the uses to which money may be put.

\section{Contemporary Experiences on Teaching and Motivation}

Although work and employment as well as productivity might be conceived of in virtually similar ways universally, there is no doubt their positions as well as the values that determine them connect the prevalent socio-economic and cultural orders.

Oshagbemi (1984) for instance observed that, whilst the principles of management as postulated by management experts have universal applicability, the practice of management has not. In practice, management often has to take into consideration and incorporate various factors that affect the workers effectiveness on the job such as culture. Culture being defined as that complex whole which includes knowledge, beliefs, art law, morals, customs and any other capabilities and habits acquired by man as a member of a society.

Though studies on teaching and motivation carried out in the Nigerian setting may find the determinants of science teacher's motivation for effective performance as manifestations of similar factors as discussed above, the cultural determination of such manifestations can not be over sighted (Idumange and Opara, 2002).Okpara (1984) believes that classical theories of motivation have origins in the developed countries of the world and bear all their value labels, as such discussion of classical theories and the Nigerian worker would appear to be a mere academic exercise. The cultural origins of the classical theories are totally different from ours and therefore theories based on data derived from such culturally different bases would be highly questionable.

It was Herzberg (1959) who asserted that satisfiers are related to success in the job recognition of that success, responsibility etc. But in Nigeria most workers including the science teacher educators do not work in where they are trained to work, or in which they have the skills. How often therefore, has someone with less potential for success and with a performance record been promoted above a hard working and conscientious worker just because the latter has no 'godfather' it would appear that the concept of 'godfatherism' is more in tune with our value orientation and we must think of ways of motivating our workers through such concepts as 'godfatherism'. He nevertheless, noted that workers are motivated in terms of the nature and quality of their personalities and the expectations with which they came when they were employed. He contended that though workers could have been motivated by, differential salary seals based on differences on cities costs and styles of living, group standards based on traditional belief systems, sensitive leadership, feedback related to good appraisal system, unsentimental methods of resolving conflicts, equal opportunity towards the development of the economy, work ethics based on relevant education, and the provision of basic amenities which would reduce the emphasis on money as a primary motivator. The prevailing socio-economic and cultural values imposed on them from outside have reduced these possibilities. For instance, at the moment Nigerian science teachers are operating colonial standards set by the colonial administration. Science teaching is more of rote learning and other theoretical conceptions rather than practicals. The standards have little or no foundation in our traditional belief systems, our patterns of achievement and performance, and our concept of success or failure. We cannot motivate people by standards action to our way of life.

However, much as we share Okpara's ideas on the importance of cultural disparities on work and motivation, there is no doubt Nigerian workers have some work ideals as their counterparts in the outside world, save for the social malformations observed today in our society. We therefore, expect that in work situations where such social malformations are played down, the results of researches carried on work and motivation outside the country might be replicated.

Ifechukwu (1977) observed that teacher welfare services, otherwise known as fringe benefits, are constantly rising when productivity does not appear to reach expected standards. He reported that many studies are of the view that fringe benefits at best give rise to job satisfaction and that there is no positive correlation between satisfaction and productivity as found in Kahr (1960). Many fringe benefits today act as the minimum expected condition for the acceptance of employment. Thus, there is a hidden cost in all fringe benefits as they are not motivators of behaviours.

It is not surprising therefore that employment productivity does not necessarily increase after the company has settled his hospital bills or after he has received his housing allowance. However, these supplementary benefits tend to trap employees as they stay to take advantage of their accumulated benefits such as retirement pension, long annual vacations or sick benefits. 
However, in the motivator-analysis, it was observed that these workers were still driven by historical motivators, even though they simultaneously yearn seriously for the progressive needs. After all said and down, it is evident that workers motivation- productivity relationship in Nigeria is not absolutely unrelated to the cause effect relationships so far established from research findings in the advanced countries(Opara, 2004). It is agreeable that some unobjective and at times inexplicable variables, perhaps emanating from the epical experience of the country, intervene in that cause effect relationship continuum, but the problems is how can such variables be played down or integrated into objective work variables.

\subsection{Enhancing Motivational Technique}

On the basis of the study that there is no one best way of Motivating the Nigerian Science Teacher Educator, that the best approach depends on the individual and the circumstances prevailing the workplace. Johnnie (1988) in his study recommended that the following attributes and circumstances of the worker appear to influence the way the worker perceives the motivational potential of a motivational activity.

- thought system and culture of Nigerian worker

- the relationship between worker and manager

- managers preferred style of leadership

- ability of the manager to determine workers' needs

- the influence of the immediate work environment on the worker

- sex and marital status of the worker

- ethnic or tribal composition of the worker in relation to that of manager

- educational level of the worker

- type of work the worker does

- the economic circumstances of the worker

- the religion of the worker

- Time the technique or activity was used.

This attributes can help to inform the Nigerian educational managers and government of the range of variables which are likely to influence a science teacher's perception of a particular motivational instrument or techniques, and therefore could determine the motivational potential of that variable in respect of a particular worker (Opara, 2005).. In other words, managers who understand the utility or motivational potentials could use the attributes to solve motivational problems of each individual in the workplace. Nigerian educational managers could predict with a fair degree of accuracy whether or not a worker will perceive a particular motivational technique favourably or not.

\section{Conclusion}

It is imperative to understand the traditional Nigerian science educator closely to be able identify his preferences, instead of relying on speculations which are western in orientation and philosophy. One serious problem which the Nigerian managers appear to encounter at work is the alien work culture and attitude (western orientated) which is in contradistinction to the work milieu of the traditional Nigerian worker. The problem seems to have escalated as a result of the apparent slowness with which the Nigerian managers appears to be adapting in an attempt to re-learn traditional African values, norms, beliefs, and practices which he un-learned in the acculturation process of acquiring western education. The problem, therefore seems to revolve around how to reconcile the traditional African value systems and schemes and the 'white-man's' industrial culture. This appears to be the bane of the matter. This problem is likely to continue to create a system of management in most Nigerian workplaces where work attitudes may remain divergent. And if this situation continues it may become extremely difficult for the Nigerian educational managers to identify the needs of the Nigerian teacher in an attempt to determine what motivates the science teachers.

The Science Teacher Educator is greatly influenced by the environment (Oguzor and Opara, 2010). The science teacher has an entity that passes through various institutional arrangements particularly at the village level, and these village activities have more or less established a 'concrete foundation' in his perceptual organization and frame of references Johnnie (1988). Those who argue that behaviour is a function of the environment hold the popular view that theories relating to determinism are positively correlated to the behaviour of the individual and his environment. If, therefore we are to accept the determinism point of view, it is not wrong to argue that the environment of the worker could have a very strong impact on him, and it may be difficult to change his work routine and culture by imposing an 
alieu system (western-oriented) on big task to be able to identify what motivated the Nigerian Science Teacher Educator and to determine a possible point of convergence between the Nigerian Science Teacher and work culture and the seemingly rural or tribal work culture of the Nigerian worker.

\section{References}

Akerele, A. (1992)."The impact of culture of human resources management" journal of personnel management, vol.5 No. 2 pp7-13

Ahiauzu A. I (1985) 'Towards a diagnostic approach to motivating the Nigerian worker' in Inanga E(ed) Managing Nigeria's economic system. London: Heinemann. Chapter 16, Pp. 200-211.

Cole G.O.H (1913) In: The social contract and discourses. In J.J Rousseau. London. J.M Dent and sons.

Connllan T.K (1978) How to improve human performances in business and industry. New York. Harper and Row

Eze N (1981) 'Motivation and work productivity among Nigerian workers' paper presented at the first national workshop on organizations behaviour and management, Ibadan.

Falade-Obalade,T and Opara, J.A(2010).Globalization and Sovereign Wealth Funds. In Ronald W.Spahr and Fernando A. Ferreira(eds) Proceedings of International Conference on Global Management, Oviedo-Spain: International Association for Scientific Knowledge.http//www.iask-web.org., pp.90-96

Freud S (1949) 'The unconscious'. In collected papers of Sigmund Freud. Vol. IV (Rivieri R) Trans. London. Hogarth Press

Hendrick K. K (1943) Psycholoanalytic view of motivation. Concept of work principles. Pp 149-153

Herzberg F. (1959) The motivation to work. John Wiley

Idumange, J.A and Opara, J.A. (2002). Politics, education and development in Nigeria: Issues and challenges. African Journal of Research in Education. 2 (1\&2), 98 -103

Ifechukwu J.O.A (1977) 'Work attitude in Nigeria'. Management in Nigeria. 13 (8)

Johnnie P.B(1988) 'Towards a diagnostic and prescriptive model for motivating the Nigerian worker: A study of two public sector organizations. Public enterprises. Vol 8, No 4

Kahn R.L (1960) Productivity and job satisfaction. Personnel psychology. 13 Pp 275-287

Nadler,A and Lawler E.E (1983) Motivation; a diagnostic approach. In Hackman, J.R, Lawler E.E and Porter , L.W (eds). Perspectives on behaviour in organization.

Oguzor, N.S and Opara, J.A.(2010).Information and Communication Technology (ICT) and Vocational Education and Training (VET) in Nigeria. In Pedro Acosta and Pedro Cravo (eds) Proceedings of International Conference on E-Activity and Leading Technologies, Oviedo-Spain: International Association for Scientific Knowledge. http//www.iask-web.org., pp.106-114

Okpara E (1984) 'How can we motivate the Nigerian worker'. In Ejiofor, P.N.O and Aniagoh, V.A , Pp 137-146

Onoge, E.O. (1992). "The positive use of ouota system in the management of human resources. Journal of personnel management. Vol. 5. No. 2 pp 15-20

Opara, J. A(1999). "Motivational Determinants of Job Productivity Among Secondary School Teachers in Port Harcourt Metropolis" Unpublished Master's Thesis, Rivers State University of Science and Technology, Port Harcourt, Rivers State, Nigeria.

Opara, J.A. (2004). Refocusing research in science, technology and mathematics, (STM) education in Nigeria: Issues, challenges and the way forward. In Akale, M. (ed.), Refocusing research in Science, Technology, and Mathematics (STM) Education.(pp. 4349).Ibadan: Science Teachers Association of Nigeria(STAN)

Opara, J.A. (2005). Career development and professionalism in (STM) education in the Niger Delta region. The secondary school teacher in perspective. In Akale, M. (ed.), Professionalism in Science, Technology, and Mathematics (STM) Education. Ibadan: Science Teachers Association of Nigeria(STAN)

Orpen. C (1979) 'The reactions of western and tribal black workers to job characteristics'. International Review of Applied Psychology. Vol 28 Pp 117-125

Oshagbemi T.A (1984) The management of culture for effective performance. In Ejiofor, P.N.O and Aniagoh, V.A, Pp 252-256

Osuagwu H.G.O (1984) 'Theories of motivation and the Nigerian environment'. In Ejiofor, P.N.O and Aniagoh, V.A Pp 104-112

Otite.O (1978) 'The study of social thought in Africa'. In Otite, O(ed) Themes in African social and political thought. Enugu. Nigeria

Vroom V.H (1964) Work and motivation. New York. John Wiley and Sons. 